Purdue University

Purdue e-Pubs

2009

\title{
The Critical Role of Channel Cross-Sectional Area in Microchannel Flow Boiling Heat Transfer
}

Tannaz Harirchian

Purdue University - Main Campus

S V. Garimella

Purdue University, sureshg@purdue.edu

Follow this and additional works at: http://docs.lib.purdue.edu/coolingpubs

Harirchian, Tannaz and Garimella, S V., "The Critical Role of Channel Cross-Sectional Area in Microchannel Flow Boiling Heat Transfer" (2009). CTRC Research Publications. Paper 129.

http://dx.doi.org/10.1016/j.ijmultiphaseflow.2009.06.005

This document has been made available through Purdue e-Pubs, a service of the Purdue University Libraries. Please contact epubs@purdue.edu for additional information. 


\title{
The Critical Role of Channel Cross-Sectional Area in Microchannel Flow Boiling Heat Transfer ${ }^{1}$
}

\author{
Tannaz Harirchian and Suresh V. Garimella ${ }^{2}$ \\ School of Mechanical Engineering and Birck Nanotechnology Center \\ Purdue University, 585 Purdue Mall, Purdue University \\ West Lafayette, IN 47907-2088 USA
}

\begin{abstract}
Experiments are conducted with a perfluorinated dielectric fluid, Fluorinert FC-77, to identify the critical geometric parameters that affect flow boiling heat transfer and flow patterns in microchannels. In recent work by the authors (Harirchian and Garimella IJMF 35:349-362, 2009), seven different silicon test pieces containing parallel microchannels of widths ranging from $100 \mu \mathrm{m}$ to $5850 \mu \mathrm{m}$, all with a depth of $400 \mu \mathrm{m}$ were tested and it was shown that for a fixed channel depth, the heat transfer coefficient was independent of channel width for microchannels of widths $400 \mu \mathrm{m}$ and larger, with the flow regimes in these microchannels being similar; nucleate boiling was also found to be dominant over a wide range of heat fluxes. In the present study, experiments are performed with five additional microchannel test pieces with channel depths of $100 \mu \mathrm{m}$ and $250 \mu \mathrm{m}$ and widths ranging from $100 \mu \mathrm{m}$ to $1000 \mu \mathrm{m}$. Flow visualizations are performed using a high-speed digital video camera to determine the flow regimes, with simultaneous local measurements of the heat transfer coefficient and pressure drop. The aim of the present study is to investigate as independent parameters the channel width and depth as well as the aspect ratio and cross-sectional area on boiling heat transfer in microchannels, based on an expanded database of experimental results. The flow visualizations and heat transfer results show that the channel cross-sectional area is the important governing parameter determining boiling mechanisms and heat transfer in microchannels. For channels with cross-sectional area exceeding a specific value, nucleate boiling is the dominant mechanism and the boiling heat transfer coefficient is independent of channel dimensions; below this threshold value of cross-sectional area, vapor confinement is observed in all channels at all heat fluxes, and the heat transfer rate increases as the microchannel cross-sectional area decreases before premature dryout occurs due to channel confinement.
\end{abstract}

Keywords: Microchannel, flow boiling, cross-sectional dimensions, confinement.

\footnotetext{
${ }^{1}$ Submitted for publication in International Journal of Multiphase Flow, May 2009, and in revised form, June 2009

${ }^{2}$ Author to whom correspondence should be addressed: (765) 494-5621, sureshg@purdue.edu
} 


\section{INTRODUCTION}

Microchannel heat sinks undergoing two-phase heat transport can provide very high heat transfer rates while maintaining the wall temperature relatively uniform, and have therefore been investigated as an attractive solution for the cooling of high-power electronics. Since the working fluid in the microchannels may be in direct contact with the electronics, the use of dielectric liquids has drawn recent attention for these applications. Although there have been a number of studies on pool boiling of perfluorinated liquids and the effect of surface enhancement (Honda and Wei 2004, McHale and Garimella 2008), investigations of flow boiling in microchannels using dielectric liquids have been limited (Chen and Garimella 2006a, Zhang, Pinjala, and Wong 2005, Warrier, Dhir, and Momoda 2002, Pate, Jones, and Bhavnani 2006).

A large number of studies have been reported on fluid flow and heat transfer mechanisms in microchannel flow boiling as reviewed in Sobhan and Garimella (2001), Garimella and Sobhan (2003), and Bertsch, Groll, and Garimella (2008). Many studies in recent years have attempted to better understand the flow patterns occurring during boiling in microchannels using different working fluids. High-speed flow visualization has been employed as an effective method to understand the physics of boiling in microchannels as well as the differences in the boiling regimes from those in conventionalsized channels (Peng and Wang 1993, Kew and Cornwell 1997, Huo et al. 2004, Chen and Garimella 2006a, Revellin et al. 2006).

Some studies have considered the effects of the diameter of circular tubes, hydraulic diameter of rectangular microchannels, or channel shape on flow boiling heat transfer (Lin, Kew, and Cornwell 2001, Saitoh, Daiguji, and Hihara 2005) and on boiling flow regimes (Jiang, Wong, and Zohar 2001, Lee et al. 2003, Dupont and Thome 2005). The effects of microchannel size and surface characteristics on bubble nucleation and flow patterns have also been investigated (Zhang et al. 2005). Lee et al. (2005) investigated the effect of microchannel height on nucleation-site activity and bubble dynamics.

As revealed by a review of the literature in Harirchian and Garimella (2008) and summarized above, there has been some consideration of the effects of microchannel diameter, width, and depth on flow 
boiling in microchannels; however, a systematic study of microchannel dimensions with a wide range of dimensional parameters on flow boiling mechanisms and heat transfer is nonexistent. In a recent study (Harirchian and Garimella 2009), the authors investigated the effects of microchannel width on boiling heat transfer and flow patterns using seven different microchannels of $400 \mu \mathrm{m}$ depth and width ranging from $100 \mu \mathrm{m}$ to $5850 \mu \mathrm{m}$. It was found that for microchannels of width larger than $400 \mu \mathrm{m}$, the heat transfer coefficient was independent of microchannel width. With the aid of high-speed flow visualization, it was observed that in these larger microchannels, nucleate boiling was dominant over a wide range of heat fluxes. In smaller microchannels (widths less than $400 \mu \mathrm{m}$ ), bubble nucleation was suppressed at a relatively low heat flux and convective boiling became dominant, resulting in higher values of heat transfer coefficient. Two types of flow regime maps were also developed and the effect of channel width on flow regime transition was investigated. Although a wide range of channel widths were tested in Harirchian and Garimella (2009), the channel depth was fixed and the effects of the dimensions and aspect ratio could not be clearly isolated.

In view of the absence of any systematic studies in the literature on the effect of microchannel dimensions on heat transfer coefficient, pressure drop, and flow patterns, the objective of the present work is to expand the previous investigation of the effect of microchannel width to study the effects of channel depth, aspect ratio, and cross-sectional area on boiling heat transfer with a dielectric fluid, FC-77. Boiling curves, heat transfer coefficients, and pressure drops are presented and flow regimes discussed for a range of microchannel sizes. The important geometrical parameters that influence boiling in microchannels are identified based on the results.

\section{EXPERIMENTAL SETUP AND TEST PROCEDURES}

\subsection{Test section}

The test section shown in Figure 1 consists of a $12.7 \mathrm{~mm} \times 12.7 \mathrm{~mm}$ silicon microchannel heat sink mounted on a printed circuit board (PCB). The PCB is installed on a quick-connect board with an insulating G10 piece sandwiched in between. A polycarbonate top cover above the test piece provides an enclosed passage for the liquid and is sealed with an O-ring. To avoid melting of the polycarbonate at 
high die temperatures, a $12.7 \mathrm{~mm} \times 12.7 \mathrm{~mm}$ Pyrex sheet of thickness $0.4 \mathrm{~mm}$ with a high melting point is sandwiched between the silicon die and the top cover and forms the top wall of the microchannels.

As detailed in Figure 2, parallel microchannels of rectangular cross-section are cut on the top surface of the silicon chip using a dicing saw. Twelve test pieces are tested with microchannel widths ranging from $100 \mu \mathrm{m}$ to $5850 \mu \mathrm{m}$ and depths ranging from $100 \mu \mathrm{m}$ to $400 \mu \mathrm{m}$. The aspect ratio (width/depth) and hydraulic diameter of these microchannels in the different test pieces take values from 0.27 to 15.55 and $96 \mu \mathrm{m}$ to $707 \mu \mathrm{m}$, respectively. The width (w), depth (d), and number (N), along with the hydraulic diameter $\left(D_{h}\right)$, aspect ratio and single channel cross-sectional area $\left(A_{c s}\right)$ of the microchannels in each heat sink are listed in Table 1. The bottom wall of the $100 \mu \mathrm{m}$-wide microchannels has an average roughness of $0.1 \mu \mathrm{m}$, while the wider microchannels have an average roughness of 0.8 to $1.4 \mu \mathrm{m}$ for the different test pieces.

A $5 \times 5$ array of resistance heat sources is fabricated on the underside of the chip, providing uniform heat flux to the base of the microchannels. Also, twenty-five temperature-sensing diodes are fabricated adjacent to each resistance heater in a like array to facilitate local measurements of the base temperature. The resistance of each heating element is calibrated for temperatures up to $130^{\circ} \mathrm{C}$. Since the resistances of all the heat sources are almost identical, they are connected in parallel and are supplied with a single DC voltage in order to provide a uniform heat flux at the base of the microchannels. The heat generated by each source is obtained from the calibrated resistance of the corresponding element and the applied voltage.

For a given current passing through a diode temperature sensor, the voltage drop across the diode depends on the temperature. To obtain the voltage-temperature relationship for each diode, the test piece is calibrated in a conventional oven. Twenty-five individual current sources are used to apply $100 \mu \mathrm{A}$ to each diode and the voltage drop across each diode is measured at seven temperatures ranging from $25^{\circ} \mathrm{C}$ to $115^{\circ} \mathrm{C}$.

More details of the individual heaters, diode temperature sensors, calibration procedures, and test section assembly are available in Chen and Garimella (2006a).

\subsection{Flow loop}


A schematic diagram of the experimental test loop is shown in Figure 3. A magnetically coupled gear pump drives the dielectric liquid, FC-77, through the closed loop. A preheater installed upstream of the test section heats the coolant to the desired subcooling temperature at the entrance of the microchannels, and a water-to-air heat exchanger located downstream of the test section cools the fluid before it enters the reservoir. The liquid is fully degassed before initiating each test using the two degassing ports and the expandable reservoir. Details of the expandable reservoir design and the degassing procedure are available in Chen and Garimella (2006b). A flow meter with a measurement range of 20-200 $\mathrm{ml} / \mathrm{min}$ monitors the flow rate through the loop and five T-type thermocouples measure the fluid temperature before and after the preheater, before and after the test section, and after the heat exchanger. The pressure in the outlet manifold of the test section is maintained at 1 atmosphere. The pressure at the inlet manifold and the pressure drop across the microchannel array are measured using a pressure transducer (Gems Sensors, 2200 series) and a differential pressure transducer (Omega, PX2300 series), respectively. A throttling valve positioned upstream of the test section serves to suppress instabilities in the microchannel heat sink. Mild flow reversals were still observed at the inlet of the microchannels at the highest heat fluxes studied, for microchannels of cross-sectional area $0.144 \mathrm{~mm}^{2}$ and smaller. However, these instabilities did not affect the inlet fluid temperature which is held constant throughout each test.

\subsection{Experimental procedures}

Experiments are conducted on the 12 test pieces to study the effects of microchannel dimensions on the boiling heat transfer and flow patterns at a fixed mass flux of $630 \mathrm{~kg} / \mathrm{m}^{2} \mathrm{~s}$. In an earlier study by the authors (Harirchian and Garimella 2008), the effects of mass flux on heat transfer coefficient and pressure drop were investigated for mass fluxes in the range of 250 to $1600 \mathrm{~kg} / \mathrm{m}^{2} \mathrm{~s}$. It was shown that heat transfer coefficient was independent of mass flux in the nucleate boiling region and the pressure drop increased with mass flux. The effect of mass flux on boiling flow patterns was also discussed in Harirchian and Garimella (2009).

Before initiating each test, the liquid in the test loop is fully degassed. It is then driven into the loop at a constant flow rate and preheated to approximately $92^{\circ} \mathrm{C}$, providing $5 \mathrm{~K}$ of subcooling at the inlet of the channels. For each test, the flow rate and the inlet fluid temperature are kept constant throughout the 
test and the uniform heat flux provided to the chip is incremented from zero to the point at which the maximum wall temperature reaches $150^{\circ} \mathrm{C}$, which is the upper limit for the safe operating temperature of the integrated heaters and temperature sensors. Heat flux values approaching critical heat flux are avoided since the corresponding temperatures could cause the solder bumps in the test chip to fail.

At each heat flux and after the system reaches a steady state, high-speed visualizations are performed simultaneously with the heat transfer and pressure drop measurements. Movies of the flow patterns are captured at various frame rates ranging from 2,000 frames per second (fps) to $24,000 \mathrm{fps}$, with the higher frame rates used for the smaller microchannels at the larger heat and mass fluxes. The images obtained from the camera are then post-processed using a MATLAB code developed in-house to enhance the quality of the images, especially for those captured at higher frame rates.

\subsection{Data reduction}

The heat transfer rate to the fluid, $\dot{q}_{n e t}$, in the microchannels is obtained from an energy balance for each heating element:

$$
\dot{q}_{\text {net }}=\dot{q}-\dot{q}_{\text {loss }}
$$

in which $\dot{q}$ is the total heat dissipated from each heat source and is obtained from $\dot{q}=V^{2} / R$, where $V$ is the applied voltage to the heating element and $R$ is the calibrated resistance. The heat loss, $\dot{q}_{\text {loss }}$, consists of losses to natural convection, radiation, and conduction through the PCB and the top cover and is experimentally determined before the test assembly is charged with coolant as described in detail in (Harirchian and Garimella 2008).

The local heat transfer coefficient is then calculated from

$$
h=\frac{q_{w}^{\prime \prime}}{\eta_{o}\left(T_{w}-T_{r e f}\right)}
$$

where $\eta_{o}$ is the overall surface efficiency of the microchannel heat sinks (Harirchian and Garimella 2008), and the range of the values for each tested heat sink is provided in Table 1. $T_{\text {ref }}$ is the local mean fluid temperature in the single-phase region and the liquid saturation temperature in the two-phase region 
and $T_{w}$ is the local microchannel wall temperature and is corrected for the microchannel base thickness using

$$
T_{w}=T_{d}-\frac{q_{b}^{\prime \prime}(t-d)}{k_{S i}}
$$

where $T_{d}$ is the temperature measured by the diode, $q_{b}^{\prime \prime}$ is the base heat flux, $t$ and $d$ are the heat sink thickness and microchannel depth, respectively, and $k_{s i}$ is the thermal conductivity of silicon.

The heat flux used in Eq. (2) is the wall heat flux and is defined as

$$
q_{w}^{\prime \prime}=\dot{q}_{n e t} /\left(A_{t} / 25\right)
$$

where $A_{t}$ is the total heated area of the microchannels

$$
A_{t}=N(w+2 d) L
$$

Here, $N$ is the number of microchannels in a heat sink, $w, d$, and $L$ are the microchannel width, depth, and length, respectively. The heat flux used in finding the wall temperature in Eq. (3) is the applied heat flux and is calculated using the chip base area, $A_{b}$, which is the same as the combined area of all the heat sources

$$
q_{b}^{\prime \prime}=\dot{q}_{n e t} /\left(A_{b} / 25\right)
$$

The calculated local heat transfer coefficients presented in this paper are based on measurements from the temperature sensor at location 3 in Figure 2, which is along the centerline of the test piece near the exit. The flow visualizations shown are also obtained at this location.

The measurement uncertainties for the flow meter and the pressure transducers are $1 \%$ and $0.25 \%$ of full scale, respectively. The uncertainties in the measurements of the channel dimensions, the T-type thermocouples and the diode temperature sensors are $\pm 15 \mu \mathrm{m}, \pm 0.3^{\circ} \mathrm{C}$ and $\pm 0.3^{\circ} \mathrm{C}$, respectively. Following a standard uncertainty analysis (Taylor 1997), the uncertainties associated with the wall heat flux and the heat transfer coefficient are obtained to be 2 to $4 \%$ and 2.2 to $4.8 \%$, respectively, for the cases considered.

\section{RESULTS AND DISCUSSION}


As mentioned earlier, a systematic investigation of boiling flow patterns and heat transfer as a function of microchannel width was recently performed by the authors (Harirchian and Garimella 2009). In the current study, additional experiments are conducted to broaden the range of microchannel dimensions considered and to explore the effects of other geometrical parameters, such as channel height, aspect ratio, and cross-sectional area. Key results from the previous study are briefly reviewed, and new findings regarding the effects of different channel dimensions on boiling mechanisms in microchannels are then discussed.

\subsection{Flow patterns}

The effects of channel dimensions and heat flux on the boiling flow patterns are discussed here based on high-speed flow visualizations. In all the flow visualization images in this paper, the flow direction is from left to right.

In Harirchian and Garimella (2009), flow regimes in microchannels of widths ranging from $100 \mu \mathrm{m}$ to $5850 \mu \mathrm{m}$, with a fixed channel depth of $400 \mu \mathrm{m}$, were discussed in detail and the effects of mass flux and channel width on flow regimes investigated. The flow patterns observed in these microchannels were categorized into five major flow regimes - bubbly, slug, churn, wispy-annular, and annular flow - and detailed descriptions along with schematic sketches of these flow regimes were provided. In the present study, these flow patterns are briefly discussed. In addition, the flow regimes in microchannels of depths in the range of $100 \mu \mathrm{m}$ to $400 \mu \mathrm{m}$ are presented and the effects of channel depth, aspect ratio, and crosssectional area on the flow regimes are discussed.

Figure 4 shows the flow patterns in the $400 \mu \mathrm{m} \times 400 \mu \mathrm{m}$ microchannels. As discussed previously in Harirchian and Garimella (2009), three flow regimes of bubbly, alternating churn and wispy-annular, and alternating churn and annular flow are observed in these microchannels. In the bubbly flow regime, isolated round and elongated bubbles nucleate at the microchannel walls and move in the flow direction as they detach from the wall after growing (Figure 4(a)). As the heat flux increases, the bubble generation rate at the walls increases and bubbles become larger as a result of bubble coalescence.

At medium heat fluxes, the flow alternates between churn and wispy-annular flow regimes as illustrated in Figure 4(b). Churn flow consists of vapor chunks transported from upstream and large 
bubbles nucleating at a high rate at the channel walls; however, at high heat fluxes, the nucleation at the walls may be suppressed. In wispy-annular flow, a vapor core is separated from the channel walls with a relatively thick and unstable liquid film. Large, irregular-shaped droplets are entrained into the vapor core. Very few nucleation sites remain in the liquid film and result in small vapor bubbles in the liquid layer. As the heat flux increases, annular flow replaces the wispy-annular flow as shown in Figure 4(c). In annular flow, the liquid layer is thinner than in wispy-annular flow, and the interface between the vapor core and the liquid film can become wavy. The liquid film thickness decreases as the heat flux increases. Small, round droplets are entrained into the vapor core, while no vapor bubbles are seen in the liquid annulus. Similar flow regimes are observed in the $1000 \mu \mathrm{m} \times 400 \mu \mathrm{m}$ (width $\times$ depth) microchannels.

In the microchannels with a larger cross-sectional area and larger aspect ratio $(1000 \mu \mathrm{m} \times 220 \mu \mathrm{m}$, $2200 \mu \mathrm{m} \times 400 \mu \mathrm{m}$, and $5850 \mu \mathrm{m} \times 400 \mu \mathrm{m}$ ), similar flow patterns of bubbly, churn/wispy-annular, and churn/annular occur, except that unlike the $400 \mu \mathrm{m} \times 400 \mu \mathrm{m}$ channels, alternating churn and wispyannular, or annular, flow regimes do not necessarily follow each other along the length of the channel; instead, they are distributed side by side across the width of the channel due to the large aspect ratio. Figure 5 shows these flow regimes in the $2200 \mu \mathrm{m} \times 400 \mu \mathrm{m}$ microchannels. It can be seen in Figure $5(\mathrm{~b}$, c) that churn flow exists on one side of the channel while wispy-annular or annular flow occupies the other side. Flow regime images for the $5850 \mu \mathrm{m} \times 400 \mu \mathrm{m}$ channels are available in Harirchian and Garimella (2009).

Figure 6 shows the flow patterns in the $100 \mu \mathrm{m} \times 400 \mu \mathrm{m}$ and $100 \mu \mathrm{m} \times 220 \mu \mathrm{m}$ (width $\times$ depth) microchannels. In these microchannels, flow patterns are different from those observed in the larger microchannels, due to the small cross-sectional area and the resulting confinement effects. Also, the still images are less clear than in the larger channels - the observations described here are based on close observation of the video images. At these microchannel sizes, bubbly flow is not established at the visualization location, and instead, slug flow commences early after the incipience of boiling. In slug flow, elongated bubbles occupy the entire cross section of the channels, separated by liquid slugs as depicted in Figure 6(a,c). At low heat fluxes, the elongated vapor bubbles can be separated by a few small bubbles in the bulk liquid. However, these small bubbles disappear at higher heat fluxes. As the 
heat flux is increased further, flow enters an alternating churn and annular regime as shown in Figure 6(b,d). The liquid layer surrounding the vapor core in the annular flow alternates between a smooth annulus and a discontinuous layer caused by bubble nucleation at the walls (Harirchian and Garimella 2009). Unlike the larger microchannels, no droplets are observed in the vapor core of the annular flow. Visualizations in the $100 \mu \mathrm{m} \times 100 \mu \mathrm{m}$ microchannels show the occurrence of annular flow right after the incipience of boiling, and no slug flow is observed. Additional images of the flow in the $100 \mu \mathrm{m} \times 400$ $\mu \mathrm{m}$ microchannels can be found in Harirchian and Garimella (2009).

Bubble confinement is also observed in the $400 \mu \mathrm{m} \times 100 \mu \mathrm{m}$ and $400 \mu \mathrm{m} \times 220 \mu \mathrm{m}$ (width $\times$ depth) microchannels. Figure 7 presents flow patterns in the latter. Although bubbly flow commences at the incipience of boiling, as the heat flux increases, some bubbles grow bigger and fill the height of the channel while expanding laterally, resulting in bubbly/slug flow as shown in Figure 7(b). At higher heat fluxes, alternating churn and annular flow occurs (Figure 7(c)).

In Figure 8, the flow patterns observed in all the microchannels investigated are summarized for a wide range of microchannel widths, depths, and aspect ratios. The abscissa shows the heat flux and the bars represents flow patterns and flow regime transitions for each microchannel size, with cross-sectional area of the channels increasing from bottom to top. Microchannel dimensions are provided on the right side of each bar as width $(\mu \mathrm{m}) \times$ depth $(\mu \mathrm{m})$, with the area of a single channel cross-section $\left(\mathrm{mm}^{2}\right)$ in parentheses.

It can be seen from this figure that in the microchannels with a cross-sectional area of $0.037 \mathrm{~mm}^{2}$ and smaller, only slug and annular regimes occur at the visualization location and bubbly flow is not established. In the larger microchannels with a cross-sectional area of up to $0.089 \mathrm{~mm}^{2}$, bubbly flow exists at very low heat fluxes and is followed by slug flow and annular flow at higher heat fluxes. A careful examination of the flow visualizations reveals that in the five smallest microchannel heat sinks with cross-sectional area smaller than $0.089 \mathrm{~mm}^{2}$, bubbles occupy the whole cross-section of the channels, resulting in bubble confinement; however, in the $250 \mu \mathrm{m} \times 400 \mu \mathrm{m}$ microchannels $\left(0.089 \mathrm{~mm}^{2}\right.$ area), although slug flow is detected, the elongated bubbles only occupy the width of the channels and do not span the entire depth; hence, the bubbles are not confined in the cross-section. 
For cross-sectional areas of $0.144 \mathrm{~mm}^{2}$ and larger, bubbly flow commences at the incipience of boiling and is followed by alternating churn and wispy-annular flow. As the heat flux is increased, an annular flow regime replaces the wispy-annular flow. In these microchannels, nucleate boiling at the walls occurs up to very high heat fluxes. For aspect ratios (width/depth) of 2.6 and smaller, the wispyannular and annular flow regimes are symmetric with respect to the channel width, while for aspect ratios of 4.5 and larger, flow symmetry is lost (Figure 5).

Considering the flow transition from bubbly or slug flow to churn/annular flow in smaller channels and to churn/wispy-annular flow in larger microchannels in Figure 8, it is seen that this transition occurs at much lower heat fluxes for microchannels with a cross-sectional area smaller than $0.089 \mathrm{~mm}^{2}$, in which confinement was also visually observed. Occurrence of slug flow and the early transition to churn/annular flow in these smaller channels affects the heat transfer behavior as will be discussed in the next section.

\subsection{Heat transfer coefficient}

Figure 9 illustrates the effect of microchannel dimensions on the heat transfer coefficient. In this figure, the heat transfer coefficient is plotted versus the wall heat flux for both single-phase and twophase flows in all the microchannels considered. As can be seen from this figure, the onset of boiling is associated with an increase in the wall heat transfer coefficient.

In Harirchian and Garimella (2009), it was shown that for a fixed channel depth of $400 \mu \mathrm{m}$, the heat transfer coefficient is independent of microchannel width for widths of $400 \mu \mathrm{m}$ or greater; however, due to the fixed channel depth, it was not clear from that work whether the determining factor was the channel width, the aspect ratio, or the cross-sectional area. Microchannels tested in the present work span a wide range of channel width, depth, aspect ratio, hydraulic diameter, and cross-sectional area, thus providing results that help clarify the dominant geometrical factor that governs boiling heat transfer in microchannels. A careful examination of Figure 9 (and review of the dimensions listed in Table 1) reveals that for microchannels with a cross-sectional area of $0.089 \mathrm{~mm}^{2}$ and larger, the heat transfer coefficient is independent of microchannel size. For smaller cross-sectional areas where bubble confinement was visually observed, the heat transfer coefficient behavior is markedly different, with the heat transfer 
coefficient being relatively higher at the lower heat fluxes. As the heat flux increases, the curves cross over, resulting in lower values of heat transfer coefficient. The largest heat transfer coefficient is seen in the $100 \mu \mathrm{m} \times 220 \mu \mathrm{m}$ microchannels, with a cross-sectional area of $0.021 \mathrm{~mm}^{2}$, before partial dryout occurs. For the $100 \mu \mathrm{m} \times 100 \mu \mathrm{m}$ microchannels, the heat transfer coefficient is relatively lower at low heat fluxes since partial dryout occurs even at very low heat fluxes.

The larger heat transfer coefficients in the smaller microchannels are attributed to the confinement effects caused by bubbles occupying the whole cross-section of the microchannels due to the small crosssectional area relative to the bubble diameter at departure. As discussed in the previous section, flow visualizations reveal that in all of the microchannels with a cross-sectional area smaller than $0.089 \mathrm{~mm}^{2}$, slug flow commences soon after incipience of boiling and flow enters the churn/annular regime at relatively low heat fluxes. Early establishment of annular flow in microchannels of very small diameter was also reported in other studies (Zhang et al. 2005, Jiang et al. 2001). As a result, bubble nucleation at the walls is not the only heat transfer mechanism, and the evaporation of the thin liquid film at the walls in the slug and annular flows also contributes to the heat transfer. Therefore, the value of heat transfer coefficient is larger for these smaller microchannels at lower heat fluxes. At high heat fluxes, a decrease in heat transfer coefficient is detected, which is due to an early partial wall dryout in these small channels. In microchannels with larger cross-sectional areas, nucleate boiling is the dominant flow regime, and hence, the heat transfer coefficient is independent of channel size. Similar trends have been reported in the literature for the dependence of confined pool boiling on plate spacing in parallel-plate configurations; as the plate spacing was reduced below the bubble departure diameter, heat transfer was enhanced in the low heat flux region due to confinement effects. As the spacing was decreased further, the heat transfer coefficient increased until it reached a maximum, after which it deteriorated with decreasing channel spacing (Geisler and Bar-Cohen 2009).

To better illustrate the effects of microchannel cross-sectional area on heat transfer coefficient, the heat transfer coefficient is plotted versus the cross-sectional area for three heat fluxes on a semi-log plot in Figure 10. This plot shows that for the lower heat fluxes of 80 and $100 \mathrm{~kW} / \mathrm{m}^{2}$, the heat transfer coefficient is relatively invariant with channel cross-sectional area for areas of $0.089 \mathrm{~mm}^{2}$ and larger 
where nucleate boiling is dominant. For smaller microchannels, the heat transfer coefficient increases with decreasing channel cross-sectional area due to vapor confinement and the contribution of thin liquid film evaporation to the heat transfer. For a low heat flux of $80 \mathrm{~kW} / \mathrm{m}^{2}$, the heat transfer coefficient reaches a maximum for the $100 \mu \mathrm{m} \times 220 \mu \mathrm{m}$ channels and decreases with further decreases in crosssectional area due to early occurrence of partial wall dryout in smaller channels. At the higher heat flux of $130 \mathrm{~kW} / \mathrm{m}^{2}$, the difference in the heat transfer coefficient values becomes smaller as the heat transfer curves for smaller microchannels approach those of the larger microchannels.

It is emphasized that the channel aspect ratio is not the determining geometric factor affecting boiling heat transfer. For instance, the $400 \mu \mathrm{m} \times 100 \mu \mathrm{m}$ and $2200 \mu \mathrm{m} \times 400 \mu \mathrm{m}$ microchannels both have comparable aspect ratios $(\sim 6)$, but the former exhibit larger heat transfer coefficients due to the smaller cross-sectional area. Similarly, the $100 \mu \mathrm{m} \times 100 \mu \mathrm{m}$ microchannels lead to larger heat transfer coefficients than the $400 \mu \mathrm{m} \times 400 \mu \mathrm{m}$ microchannels although the aspect ratios of the channels in both chips are identical. It is also clear from the results that the smallest dimension of the microchannel is not the key factor; although all the microchannels with a common smallest dimension of $400 \mu \mathrm{m}$ have similar values of heat transfer coefficient, the $100 \mu \mathrm{m} \times 400 \mu \mathrm{m}, 100 \mu \mathrm{m} \times 220 \mu \mathrm{m}$, and $100 \mu \mathrm{m} \times 100 \mu \mathrm{m}$ microchannels (all with a common smallest dimension of $100 \mu \mathrm{m}$ ) exhibit different values of heat transfer coefficient. As mentioned before, the reason is the dependence of heat transfer coefficient on crosssectional area for channels with areas smaller than $0.089 \mathrm{~mm}^{2}$ due to vapor confinement.

\subsection{Boiling curve}

The effect of microchannel size on the boiling curve is shown in Figure 11. Both single-phase and two-phase regions are included in this plot. In the single-phase region, the wall excess temperature (xaxis) is calculated with respect to the mean fluid temperature, while in the two-phase region, the saturation temperature of the liquid is employed. The onset of boiling is associated with a sharp drop in the wall temperature as can be seen in this figure. When sufficiently small heat flux increments were used during the test, this temperature overshoot was observed with all the test pieces.

For microchannels of cross-sectional area $0.089 \mathrm{~mm}^{2}$ and larger, the boiling curves cluster together beyond the onset of nucleate boiling, indicating the dominance of nucleate boiling. As boiling starts in 
these microchannels, the wall temperature shows a weak dependency on the heat flux. This is consistent with the dominant nucleate boiling flow regime that was observed through the flow visualizations. As the heat flux increases, the wall temperature becomes more dependent on the heat flux and the boiling curves deviate for different channel sizes as convective boiling dominates.

For the microchannels with smaller cross-sectional areas, the wall temperature increases with increasing wall heat flux and the boiling curves do not collapse on to those of the larger microchannels. The strong dependence of the wall temperature on the heat flux for these microchannels can be explained based on the flow visualizations which reveal that thin-film evaporation and forced convection in the thin liquid film surrounding the vapor slug or annulus, rather than nucleate boiling, are the main heat transfer mechanisms in the smaller channels.

\subsection{Pressure drop}

The pressure drop as a function of the average wall heat flux is shown in Figure 12 for all the microchannel sizes considered. The two-phase region can be clearly distinguished from the single-phase region by the sharp change in the slope of the curves. In the single-phase region, the pressure drop slightly decreases with increasing heat flux due to the reduction in liquid viscosity as the liquid temperature increases. In the two-phase region, the pressure drop is strongly dependent on heat flux and increases rapidly and almost linearly with increasing heat flux due to the acceleration of vapor. This trend in pressure drop has been reported in many studies (Warrier et al. 2002, Chen and Garimella 2006a, Pate et al. 2006).

In both the single-phase and two-phase regions, the pressure drop increases with decreasing microchannel cross-sectional area at a given heat flux. In the two-phase region, the slope of the line also increases as the channel area decreases, with much larger pressure drops for smaller channels at higher heat fluxes.

It can also be seen that for the microchannels with similar cross-sectional areas and different aspect ratios, pressure drops are similar in value (e.g., $250 \mu \mathrm{m} \times 400 \mu \mathrm{m}$ and $400 \mu \mathrm{m} \times 220 \mu \mathrm{m}$ microchannels).

\section{CONCLUSIONS}


The effect of channel dimensions on microchannel flow boiling heat transfer has been investigated through a comprehensive set of experiments. Flow visualizations and heat transfer results show that the microchannel width, depth, or aspect ratio individually do not determine boiling mechanisms and heat transfer in microchannels; instead, it is the cross-sectional area of the microchannels that plays a determining role.

For microchannels of cross-sectional area smaller than $0.089 \mathrm{~mm}^{2}$, slug flow commences at the incipience of boiling, and the flow enters a churn/annular flow regime at relatively low heat fluxes. Vapor confinement in these microchannels results in larger values of heat transfer coefficient as the heat transfer comprises both nucleate boiling and liquid film evaporation mechanisms.

In microchannels with a cross-sectional area of $0.089 \mathrm{~mm}^{2}$ and larger, nucleate boiling is dominant up to very high heat fluxes, resulting in an independence of heat transfer coefficient on channel dimensions. Also, the wall temperature does not vary much with heat flux in these channels due to the dominance of nucleate boiling. In these microchannels, as the aspect ratio increases, flow patterns become asymmetric with respect to the channel width, i.e. two different flow patterns might be distributed side by side across the width of the channel.

The pressure drop decreases slightly with heat flux in the single-phase region and increases rapidly with heat flux in the two-phase region. For a fixed wall heat flux, pressure drop increases with decreasing channel cross-sectional area.

Confinement effects in microchannels are very important as they affect the heat transfer mechanisms in flow boiling; hence, it is very important to quantitatively determine the conditions at which vapor confinement occurs and microscale effects become present. In ongoing work by the authors, a quantitative transition criterion is under development for the emergence of microscale effects in flow boiling.

\section{Acknowledgements}

Financial support from the State of Indiana $21^{\text {st }}$ Century Research and Technology Fund and from the Cooling Technologies Research Center, an NSF Industry/University Cooperative Research Center at 
Purdue University, is gratefully acknowledged. The authors thank Bruce Myers of Delphi Electronics and Safety, Kokomo, Indiana, for providing the silicon test pieces.

\section{REFERENCES}

Bergles, A. E., Lienhard, J. H., Kendall, G. E., and Griffith, P., 2003. Boiling and Evaporation in Small Diameter Channels. Heat Transfer Engineering 24 (1), 18-40.

Bertsch, S. S., Groll, E. A., and Garimella, S. V., 2008. Review and Comparative Analysis of Studies on Saturated Flow Boiling in Small Channels. Nanoscale and Microscale Thermophysical Engineering 12 (3), 187-227.

Chen, T. and Garimella, S. V., 2006a. Measurements and High-Speed Visualization of Flow Boiling of a Dielectric Fluid in a Silicon Microchannel Heat Sink. International Journal of Multiphase Flow 32 (8), 957-971.

Chen, T. and Garimella S. V., 2006b. Effect of Dissolved Air on Subcooled Flow Boiling of a Dielectric Coolant in a Microchannel Heat Sink. Journal of Electronic Packaging 128 (4), 398-404.

Dupont, V. and Thome, R., 2005. Evaporation in Microchannels: Influence of the Channel Diameter on Heat Transfer. Microfluidics and Nanofluidics 1 (2), 119-127.

Garimella, S. V. and Sobhan, C. B., 2003. Transport in Microchannels - A Critical Review. Annual Review of Heat Transfer 13, 1-50.

Geisler, K. J. L. and Bar-Cohen, A., 2009. Confinement Effects on Nucleate Boiling and Critical Heat Flux in Buoyancy-Driven Microchannels. International Journal of Heat and Mass Transfer 52 (11-12), 2427-2436.

Harirchian, T. and Garimella, S. V., 2009. Effects of Channel Dimension, Heat Flux, and Mass Flux on Flow Boiling Regimes in Microchannels. International Journal of Multiphase Flow 35, 349-362.

Harirchian, T. and Garimella, S. V., 2008. Microchannel Size Effects on Local Flow Boiling Heat Transfer to a Dielectric Fluid. International Journal of Heat and Mass Transfer 51, 3724-3735.

Honda, H. and Wei, J. J., 2004. Enhanced Boiling Heat Transfer from Electronic Components by Use of Surface Microstructures. Experimental Thermal and Fluid Science 28, 159-169. 
Huo, X., Chen, L., Tian, Y.S., and Karayiannis, T. G., 2004. Flow Boiling and Flow Regimes in Small Diameter Tubes. Applied Thermal Engineering 24, 1225-1239.

Jiang, L., Wong, M., and Zohar, Y., 2001. Forced Convection Boiling in a Microchannel Heat Sink. Journal of Microelectromechanical Systems 10, 80-87.

Kandlikar, S., 2004. Heat Transfer Mechanisms During Flow Boiling in Microchannels. Journal of Heat Transfer 126, 8-16.

Kew, P. A. and Cornwell, K., 1997. Correlations for the Prediction of Boiling Heat Transfer in SmallDiameter Channels. Applied Thermal Engineering 17, 705-715.

Lee, M., Cheung, L. S. L., Lee, Y., and Zohar, Y., 2005. Height Effect on Nucleation-Site Activity and Size-Dependent Bubble Dynamics in Microchannel Convective Boiling. Journal of Micromechanics and Microengineering 15, 2121-2129.

Lee, M., Wong, Y. Y., Wong, M., and Zohar, Y., 2003. Size and Shape Effects on Two-Phase Flow Patterns in Microchannel Forced Convection Boiling. Journal of Micromechanics and Microengineering $13,155-164$.

Lin, S., Kew, P. A., and Cornwell, K., 2001. Flow Boiling of Refrigerant R141B in Small Tubes. Chemical Engineering Research and Design 79 (4), 417-424.

Liu, D., Lee, P. S., and Garimella, S. V., 2005. Prediction of the Onset of Nucleate Boiling in Microchannel Flow. International Journal of Heat and Mass Transfer 48, 5134-5149.

McHale, J. P. and Garimella, S. V., 2008. Measurement of Bubble Nucleation Characteristics in Pool Boiling of a Wetting Liquid on Smooth and Roughened Surfaces. 2008 ASME Summer Heat Transfer Conference, Jacksonville, FL, USA, HT2008-56179.

Pate, D. P., Jones, R. J., and Bhavnani, S. H., 2006. Cavity-Induced Two-Phase Heat Transfer in Silicon Microchannels. Proceedings of the Intersociety Conference on Thermal and Thermomechanical Phenomena and Emerging Technologies in Electronic Systems, 71-78.

Peng, X. F. and Wang, B. X., 1993. Forced Convection and Flow Boiling Heat Transfer for Liquid Flowing Through Microchannels. International Journal of Heat and Mass Transfer 36 (14), 3421-3427. 
Revellin, R., Dupont, V., Ursenbacher, T., Thome, J. R., and Zun, I., 2006. Characterization of Diabatic Two-Phase Flows in Microchannels: Flow Parameter Results for R-134a in a $0.5 \mathrm{~mm}$ Channel. International Journal of Multiphase Flow 32, 755-774.

Saitoh, S., Daiguji, H., and Hihara, E., 2005. Effect of Tube Diameter on Boiling Heat Transfer of R134a in Horizontal Small-Diameter Tubes. International Journal of Heat and Mass Transfer 48 (23-24), 4973-4984.

Sobhan, C. B. and Garimella, S. V., 2001. A Comparative Analysis of Studies on Heat Transfer and Fluid Flow in Microchannels. Microscale Thermophysical Engineering 5, 293-311.

Taylor, J. R., 1997. An Introduction to Error Analysis, $2^{\text {nd }}$ Edition. University Science Books.

Warrier, G. R., Dhir, V. K., and Momoda, L. A., 2002. Heat Transfer and Pressure Drop in Narrow Rectangular Channels. Experimental Thermal and Fluid Science 26, pp. 53-64.

Zhang, H. Y., Pinjala, D., and Wong T. N., 2005. Experimental Characterization of Flow Boiling Heat Dissipation in a Microchannel Heat Sink with Different Orientations. Proceeding of $7^{\text {th }}$ Electronics Packaging Technology Conference, EPTC 2, 670-676.

Zhang, L., Wang, E. N., Goodson, K. E., and Kenny, T. W., 2005. Phase Change Phenomena in Silicon Microchannels. International Journal of Heat and Mass Transfer 48, 1572-1582. 


\section{LIST OF TABLES}

Table 1. Microchannel dimensions (the microchannel widths and depths are referred to in the rest of the paper by the nominal values that are provided in the table).

\section{LIST OF FIGURES}

Figure 1. Microchannel test section..

Figure 2. Integrated heaters and temperature sensors in the microchannel test piece.

Figure 3. Schematic illustration of the flow loop.

Figure 4. Flow patterns in the $400 \mu \mathrm{m} \times 400 \mu \mathrm{m}$ microchannels.

Figure 5. Flow patterns in the $2200 \mu \mathrm{m} \times 400 \mu \mathrm{m}$ microchannels.

Figure 6. Flow patterns in the (a, b) $100 \mu \mathrm{m} \times 400 \mu \mathrm{m}$, and (c, d) $100 \mu \mathrm{m} \times 220 \mu \mathrm{m}$ microchannels.

Figure 7. Flow patterns in the $400 \mu \mathrm{m} \times 220 \mu \mathrm{m}$ microchannels.

Figure 8. Summary of boiling flow patterns in the microchannel heat sinks; the microchannel dimensions are presented as width $(\mu \mathrm{m}) \times$ depth $(\mu \mathrm{m})$ with the single channels cross-sectional area $\left(\mathrm{mm}^{2}\right)$ in parentheses.

Figure 9. Effect of microchannel dimensions $(\mu \mathrm{m} \times \mu \mathrm{m})$ on heat transfer coefficients.

Figure 10. Effect of microchannel cross-sectional area on heat transfer coefficient, with trend lines added.

Figure 11. Effect of microchannel dimensions $(\mu \mathrm{m} \times \mu \mathrm{m})$ on boiling curves.

Figure 12. Effect of microchannel dimensions on pressure drop. 
Table 1. Microchannel dimensions (the microchannel widths and depths are referred to in the rest of the paper by the nominal values that are provided in the table).

\begin{tabular}{ccccccc}
\hline $\begin{array}{c}\mathrm{w}(\mu \mathrm{m}) \\
\text { (actual values) }\end{array}$ & $\begin{array}{c}\mathrm{d}(\mu \mathrm{m}) \\
\text { (actual values) }\end{array}$ & $\mathrm{N}$ & $\begin{array}{c}\mathrm{D}_{\mathrm{h}} \\
(\mu \mathrm{m})\end{array}$ & $\mathrm{w} / \mathrm{d}$ & $\begin{array}{c}\mathrm{A}_{\mathrm{cs}} \\
\left(\mathrm{mm}^{2}\right)\end{array}$ & $\eta_{o}(\%)$ \\
\hline $100(99)$ & $100(94)$ & 61 & 96 & 1.05 & 0.009 & $96.7-98.0$ \\
$100(97)$ & $220(217)$ & 63 & 134 & 0.45 & 0.021 & $97.7-98.5$ \\
$100(102)$ & $400(369)$ & 60 & 159 & 0.27 & 0.037 & $97.2-98.8$ \\
$250(240)$ & $400(371)$ & 35 & 291 & 0.64 & 0.089 & $97.3-99.1$ \\
$400(398)$ & $100(65)$ & 25 & 111 & 6.12 & 0.026 & $97.4-98.4$ \\
$400(400)$ & $220(197)$ & 25 & 264 & 2.03 & 0.079 & $96.5-98.5$ \\
$400(395)$ & $400(365)$ & 24 & 379 & 1.08 & 0.144 & $97.5-99.0$ \\
$700(686)$ & $400(376)$ & 14 & 486 & 1.83 & 0.258 & $98.5-99.6$ \\
$1000(1024)$ & $220(226)$ & 10 & 370 & 4.53 & 0.231 & $96.0-99.0$ \\
$1000(978)$ & $400(374)$ & 10 & 541 & 2.62 & 0.366 & $99.2-99.7$ \\
$2200(2203)$ & $400(370)$ & 5 & 634 & 5.95 & 0.815 & $99.6-99.9$ \\
$5850(5851)$ & $400(376)$ & 2 & 707 & 15.55 & 2.201 & $99.8-99.9$ \\
\hline
\end{tabular}




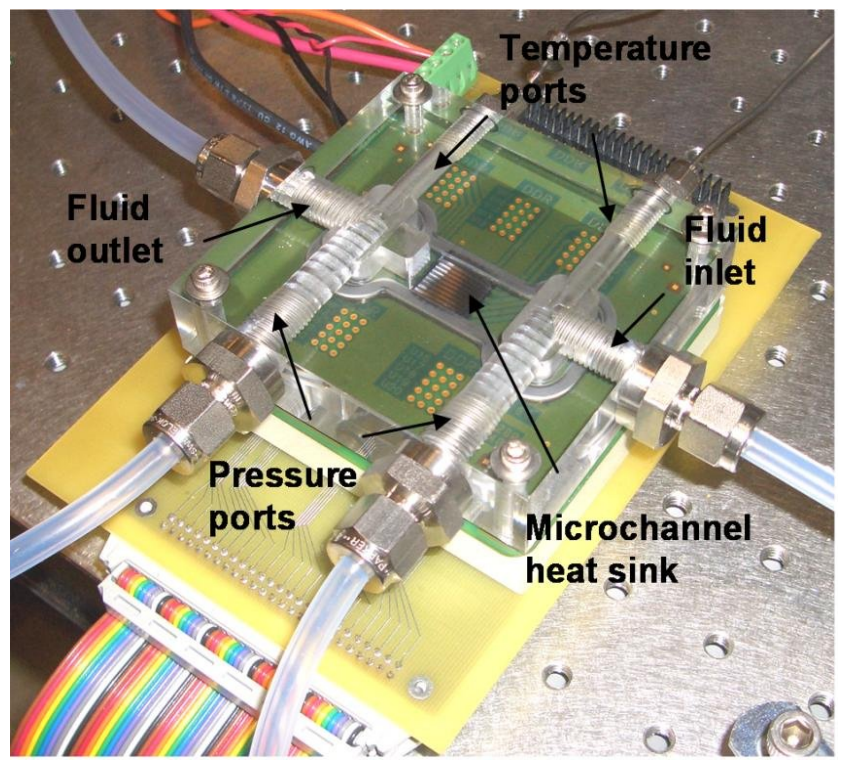

Figure 1. Microchannel test section. 

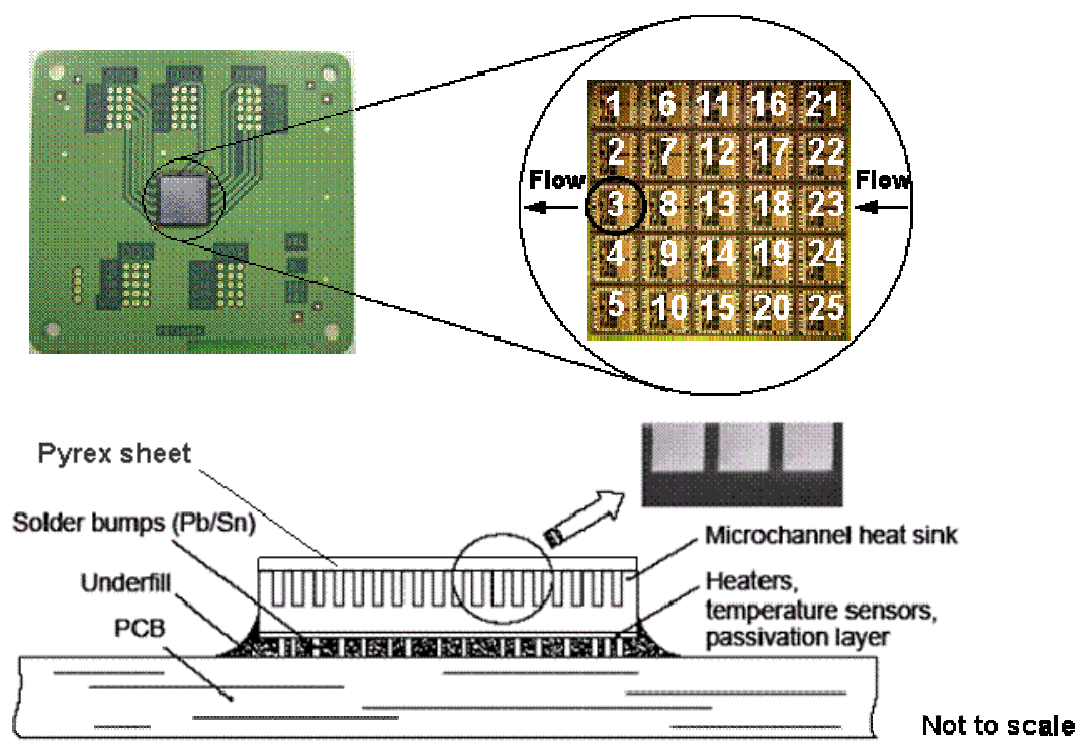

Figure 2. Integrated heaters and temperature sensors in the microchannel test piece. 


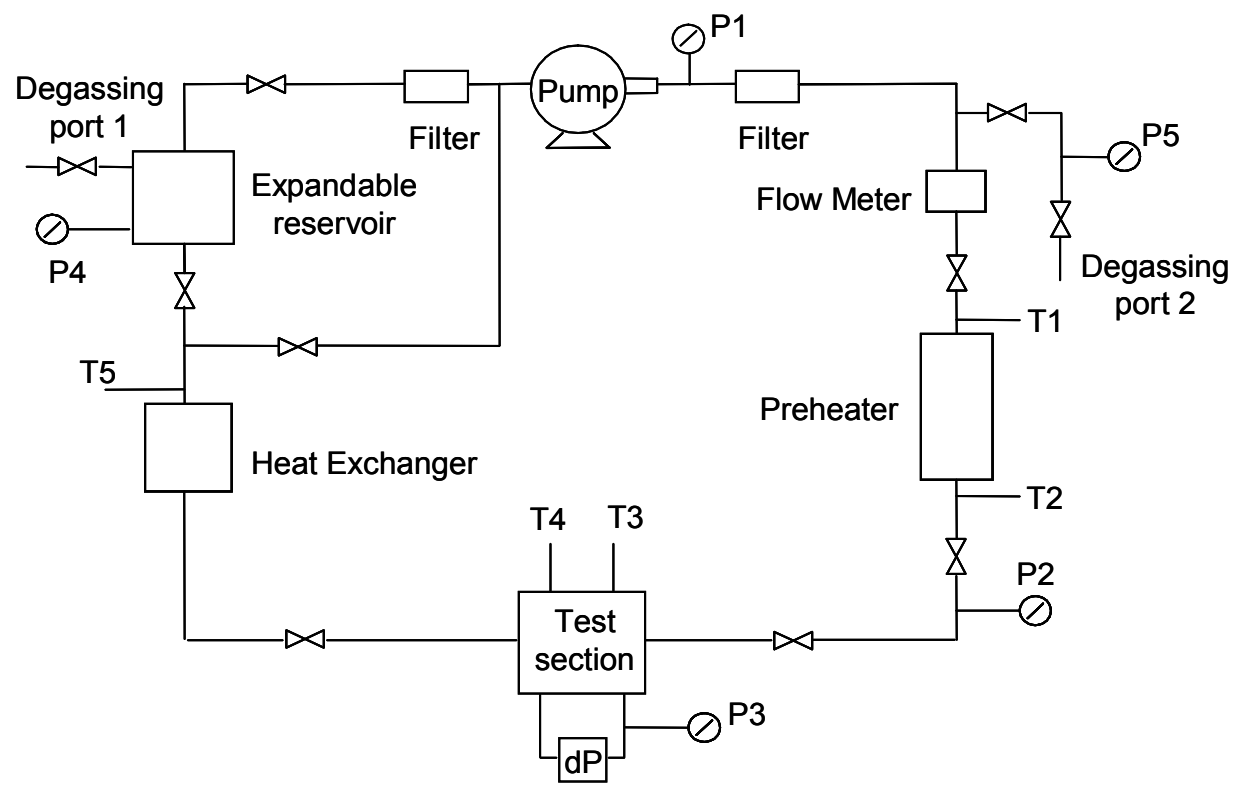

Figure 3. Schematic illustration of the flow loop. 

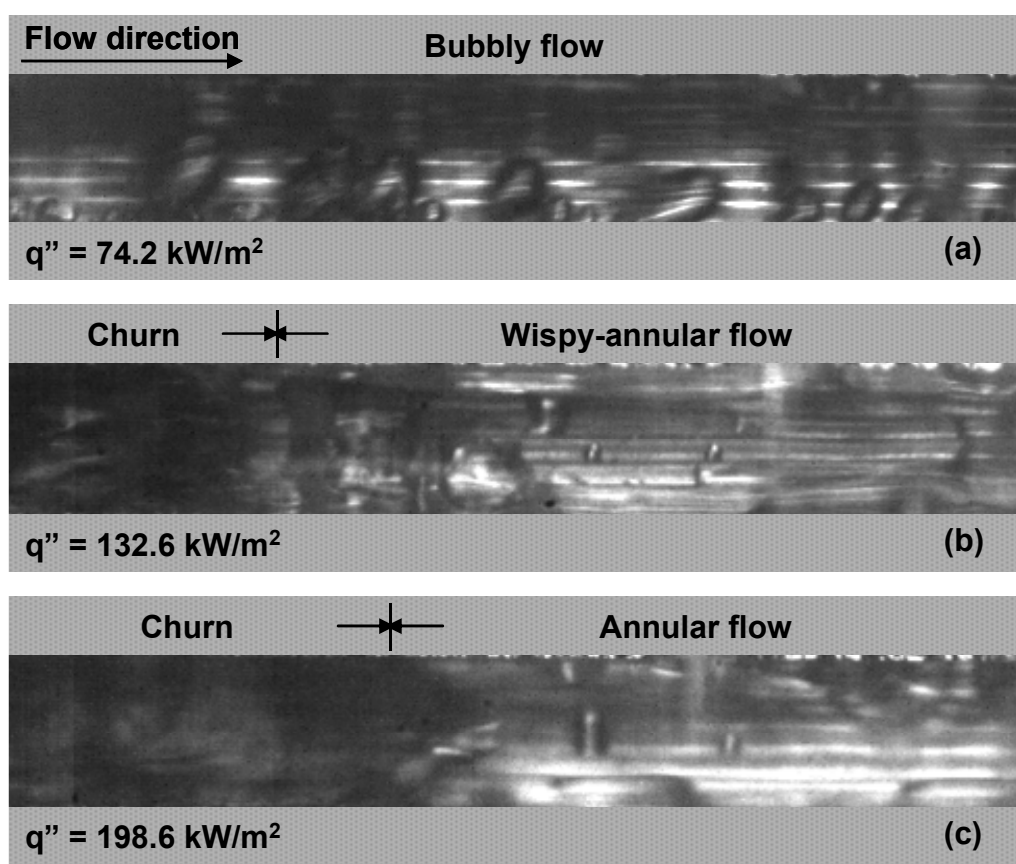

Figure 4. Flow patterns in the $400 \mu \mathrm{m} \times \mathbf{4 0 0} \mu \mathrm{m}$ microchannels. 


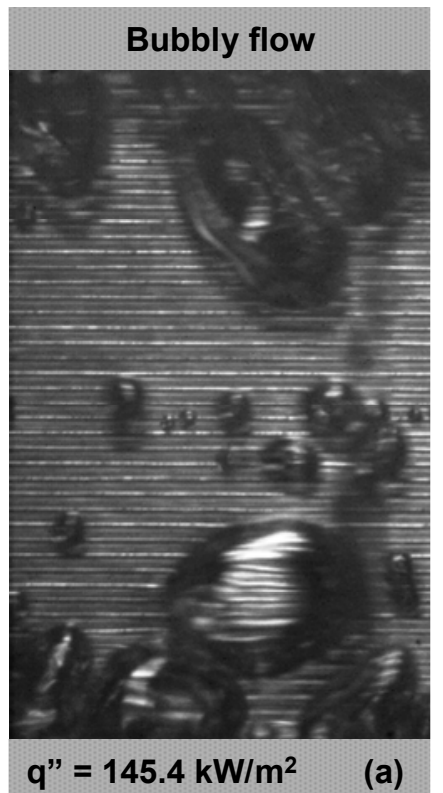

$q "=145.4 \mathrm{~kW} / \mathrm{m}^{2}$

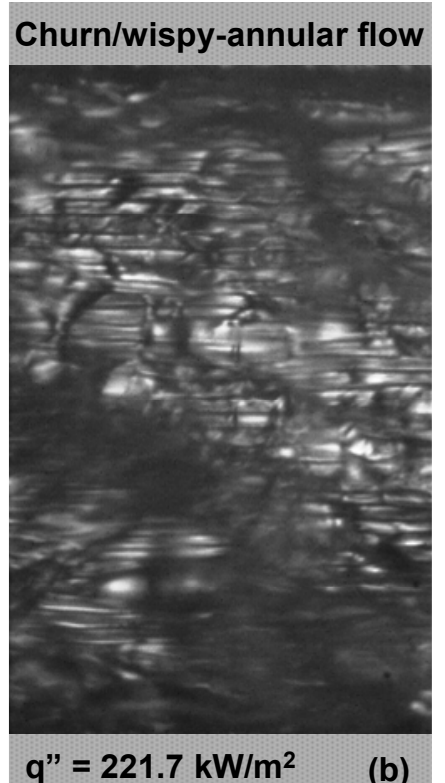

(b)

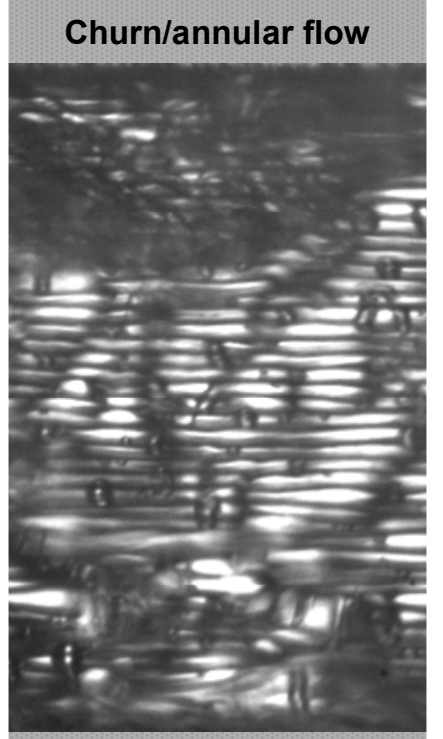

$q^{\prime \prime}=280 \mathrm{~kW} / \mathrm{m}^{2}$

(c)

Figure 5. Flow patterns in the $2200 \mu \mathrm{m} \times 400 \mu \mathrm{m}$ microchannels. 


\begin{tabular}{|c|c|}
\hline (Liquid slug) & Slug flow (Elongated vapor bubble) \\
\hline$\searrow$ & 1 \\
\hline$q^{\prime \prime}=28.1 \mathrm{~kW} / \mathrm{m}^{2}$ & (a) \\
\hline Churn flow & Annular flow \\
\hline$q^{\prime \prime}=102.7 \mathrm{~kW} / \mathrm{m}^{2}$ & (b) \\
\hline (Liquid slug) & Slug flow (Elongated vapor bubble) \\
\hline $\cos$ & cena \\
\hline$q^{\prime \prime}=48.3 \mathrm{~kW} / \mathrm{m}^{2}$ & (c) \\
\hline Annular flow & Churn flow \\
\hline$q^{\prime \prime}=101.5 \mathrm{~kW} / \mathrm{m}^{2}$ & (b) \\
\hline
\end{tabular}

Figure 6. Flow patterns in the (a, b) $100 \mu \mathrm{m} \times 400 \mu \mathrm{m}$, and (c, d) $100 \mu \mathrm{m} \times 220 \mu \mathrm{m}$ microchannels. 

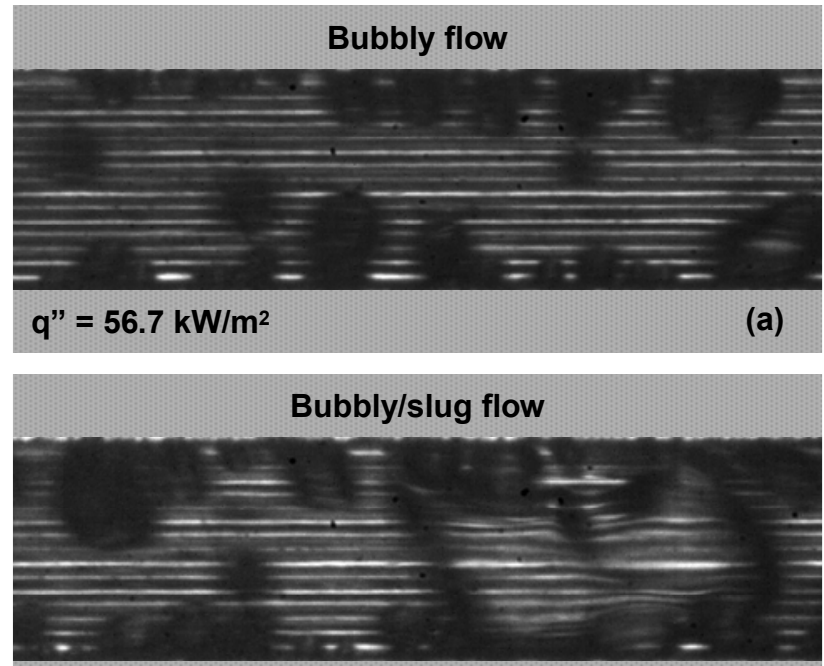

$q^{\prime \prime}=69.9 \mathrm{~kW} / \mathrm{m}^{2}$

(b)

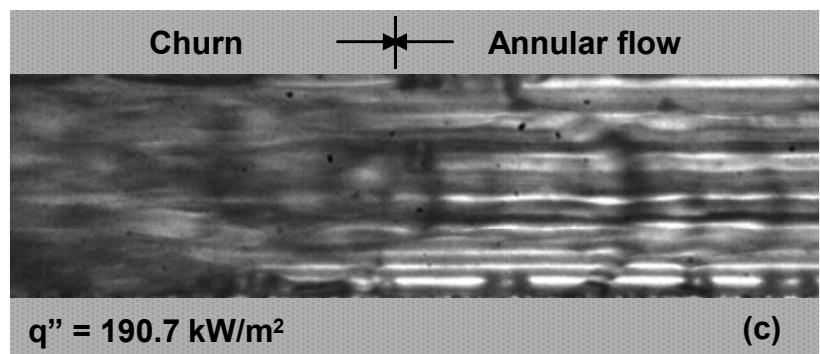

Figure 7. Flow patterns in the $400 \mu \mathrm{m} \times 220 \mu \mathrm{m}$ microchannels. 


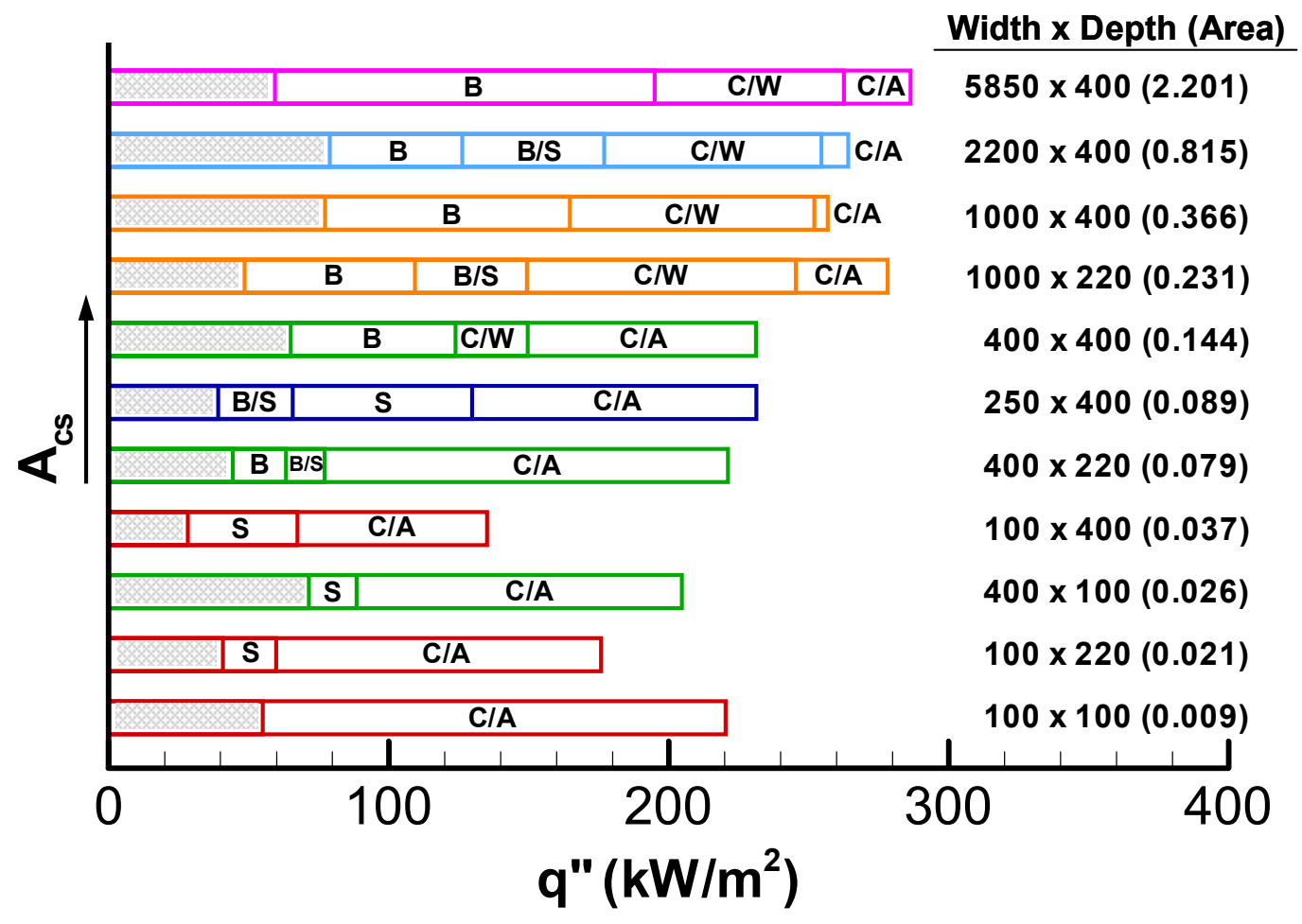

B: Bubbly S: Slug C: Churn W: Wispy-annular $\quad$ A: Annular
B/S: Intermittent bubbly/slug flow
C/W: Intermittent churn/wispy-annular flow
C/A: Intermittent churn/annular flow
: Single-phase flow

Figure 8. Summary of boiling flow patterns in the microchannel heat sinks; the microchannel dimensions are presented as nominal width $(\mu \mathrm{m}) \times$ nominal depth $(\mu \mathrm{m})$ with the actual singlechannel cross-sectional area $\left(\mathrm{mm}^{2}\right)$ in parentheses. 


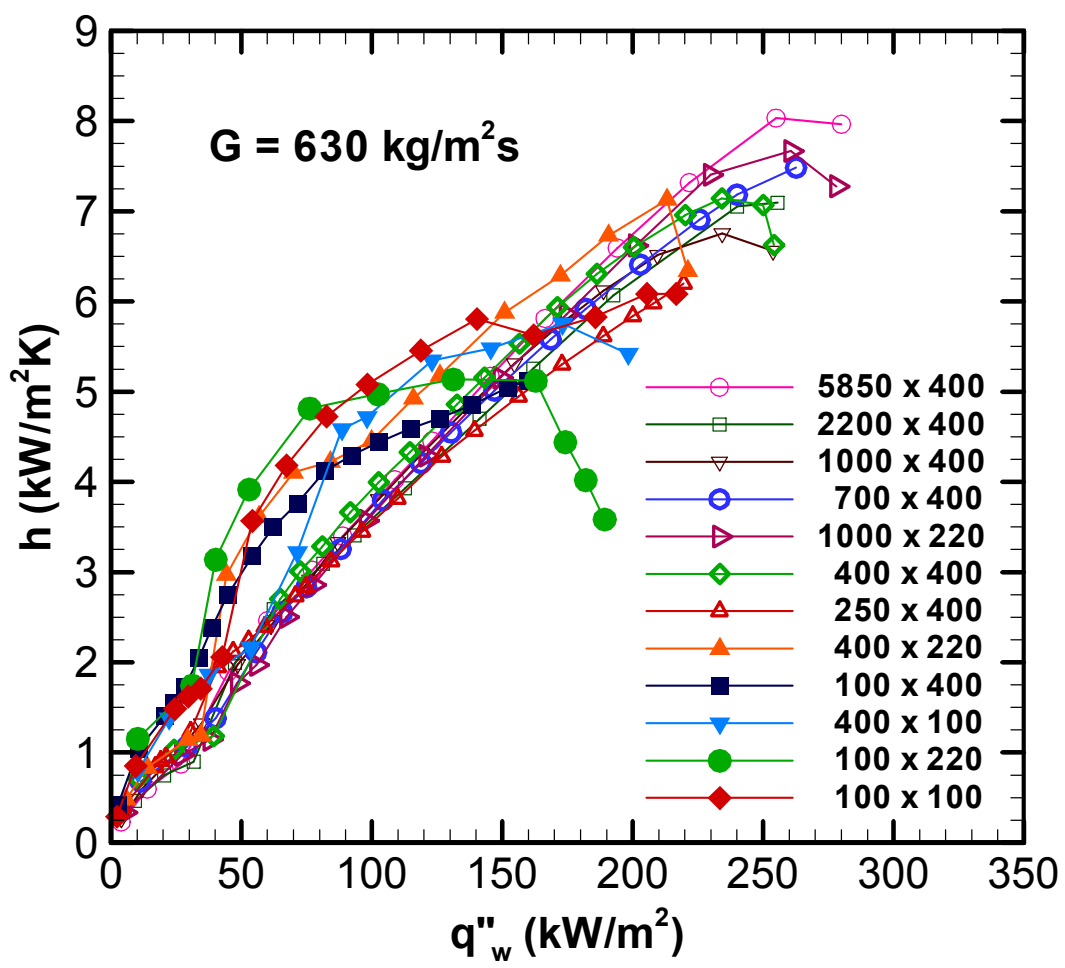

Figure 9. Effect of microchannel dimensions $(\mu \mathrm{m} \times \mu \mathrm{m})$ on heat transfer coefficients. 


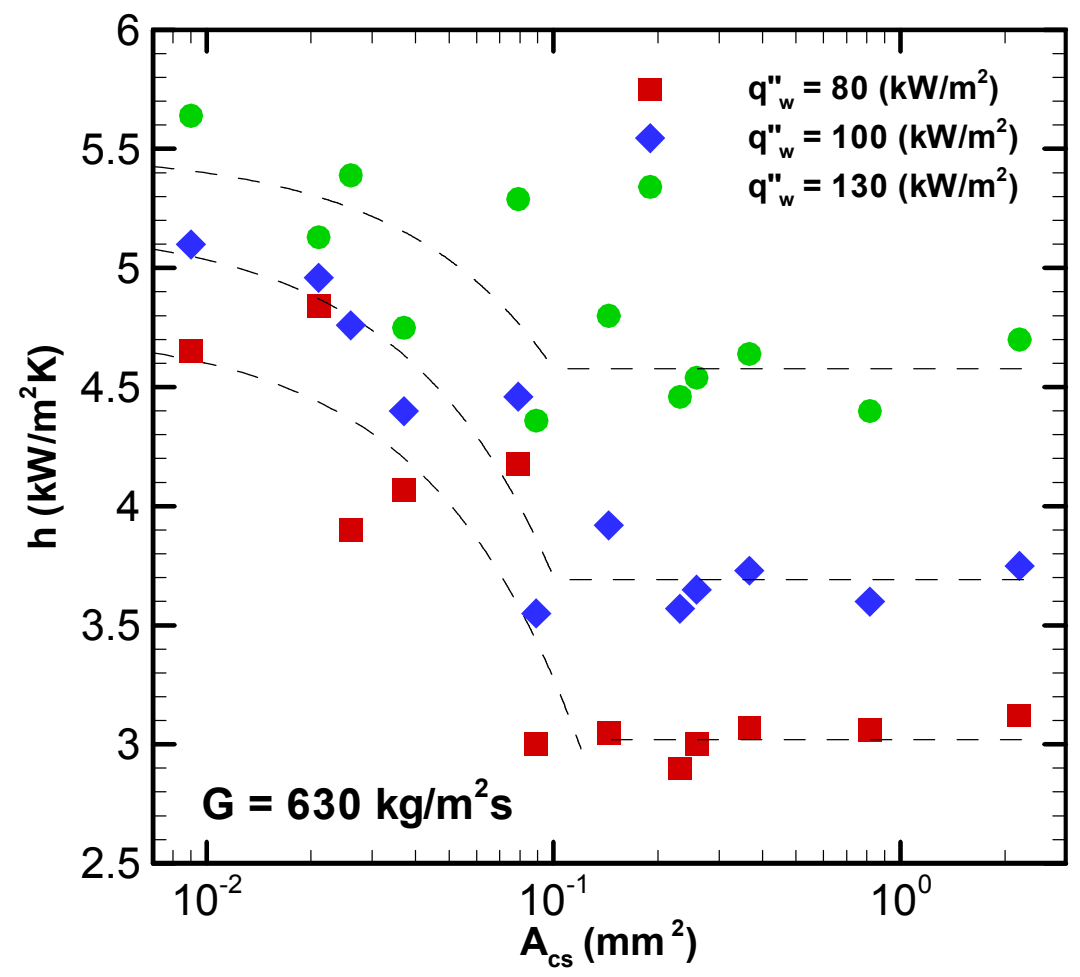

Figure 10. Effect of microchannel cross-sectional area on heat transfer coefficient, with trend lines added. 


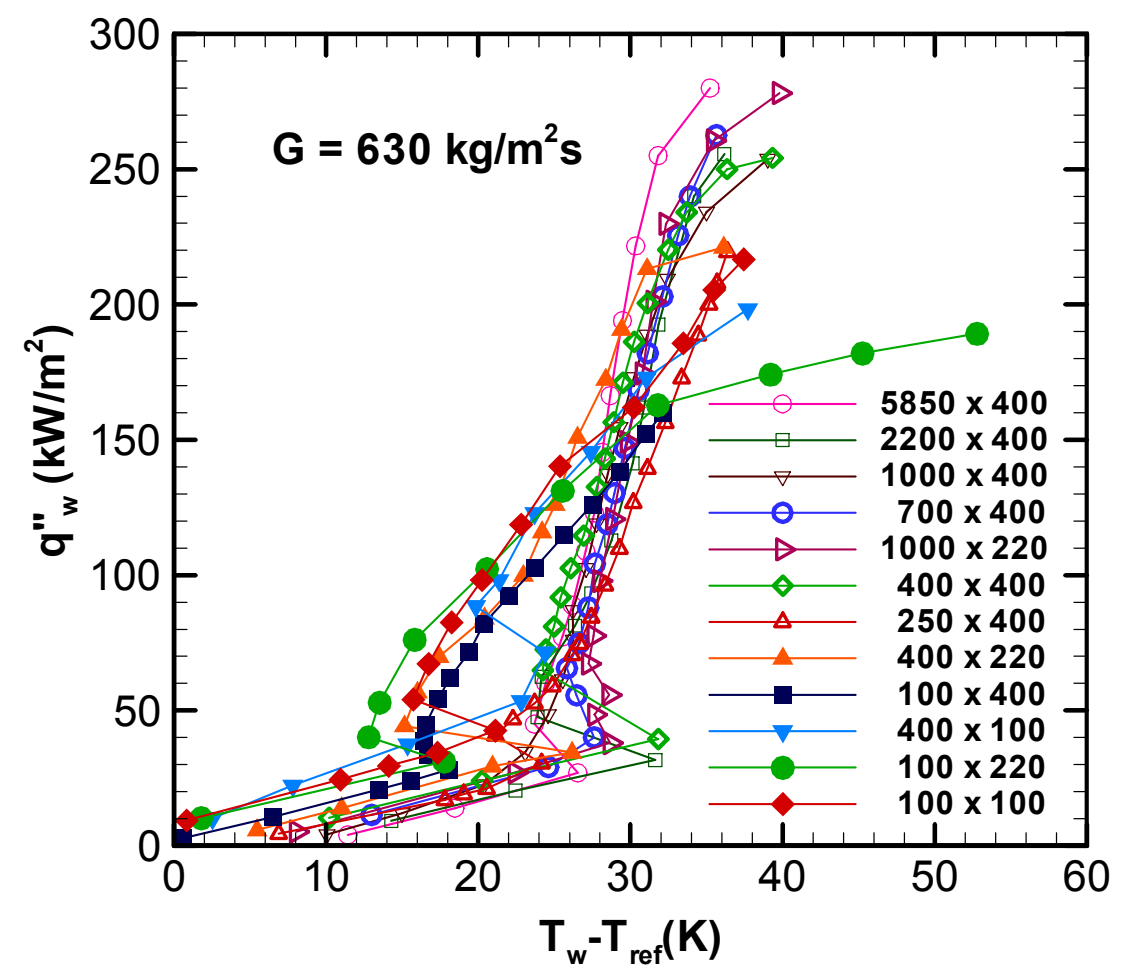

Figure 11. Effect of microchannel dimensions $(\mu \mathrm{m} \times \mu \mathrm{m})$ on boiling curves. 


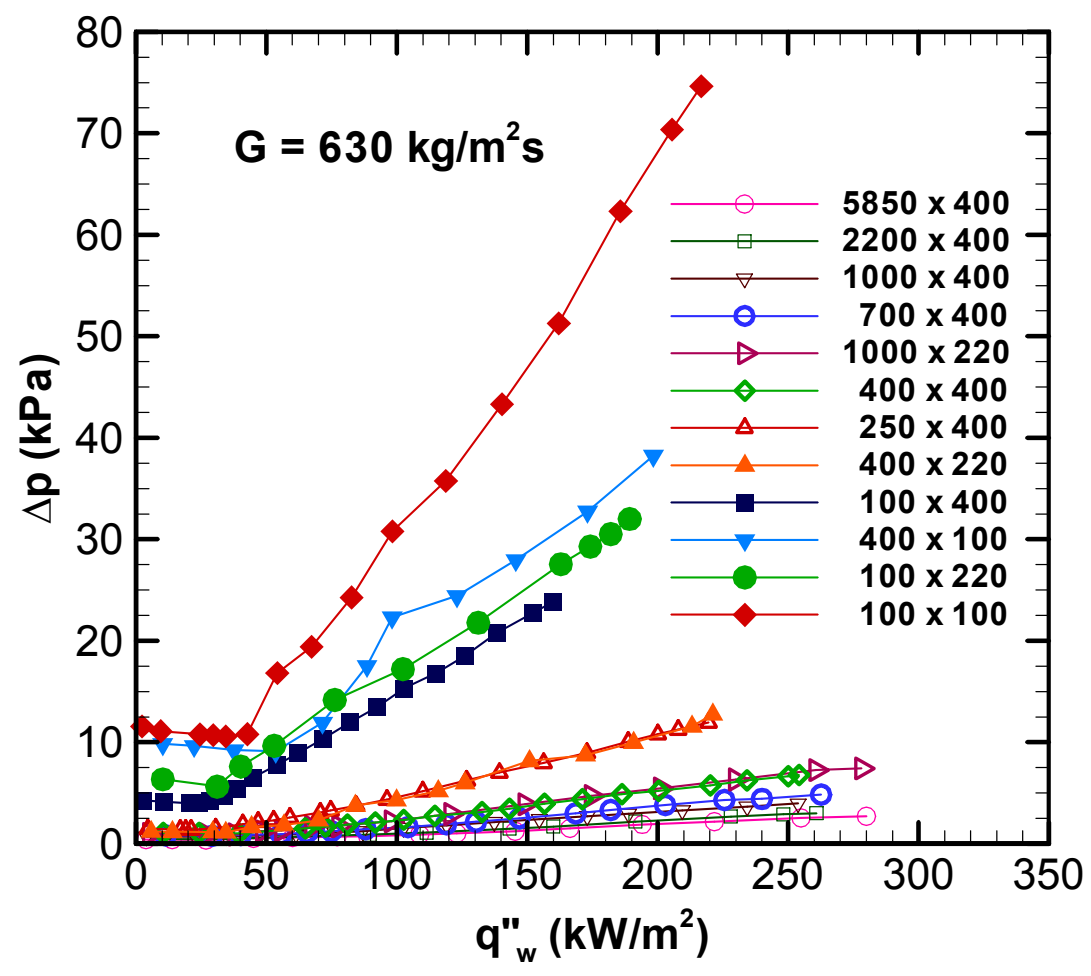

Figure 12. Effect of microchannel dimensions on pressure drop. 